\title{
Advances in visible light-mediated oxidative coupling reactions
}

\author{
Guoting Zhang a, Changliang Bian a, Aiwen Lei a,b,* \\ a College of Chemistry and Molecular Sciences, the Institute for Advanced Studies, Wuhan University, Wuhan 430072, Hubei, China \\ b National Research Center for Carbohydrate Synthesis, Jiangxi Normal University, Nanchang 330022, Jiangxi, China
}

\section{A R T I C L E I N F O}

Article history:

Received 7 April 2015

Accepted 23 April 2015

Published 20 September 2015

\section{Keywords:}

Oxidative cross-coupling

Photoredox catalysis

Visible light

Homogeneous catalysis

Single-electron-transfer

\section{A B S T R A C T}

A variety of visible light-mediated oxidative cross-coupling reactions featuring good atom/step economy and overall sustainability have emerged as efficient new methods for the construction of $\mathrm{C}-\mathrm{C}$ bonds under mild conditions. Furthermore, a wide range of different oxidative cross-coupling reactions have been developed during the last 5 years using photoredox catalysis. This review provides a summary of recent advances in the field of photoredox-catalyzed oxidative cross-coupling reactions, and could be used as a reference guide or a platform to inspire the development of new photoredox-catalyzed oxidative cross-coupling reactions with improved efficiency and selectivity.

(C) 2015, Dalian Institute of Chemical Physics, Chinese Academy of Sciences. Published by Elsevier B.V. All rights reserved.

\section{Introduction}

The development of efficient methods for the formation of new chemical bonds under mild and green conditions is one of the fundamental challenges of synthetic chemistry. Transition-metal catalyzed cross-coupling reactions have been proven to be powerful tools for the formation of $\mathrm{C}-\mathrm{C}, \mathrm{C}-\mathrm{N}, \mathrm{C}-\mathrm{O}$ and $\mathrm{C}-\mathrm{S}$ bonds, and reactions of this type have been widely applied in both academia and industry [1-6]. However, classic cross-coupling reactions between electrophiles and nucleophiles generally require separate pre-functionalization and de-functionalization steps, which can reduce the overall efficiency of the transformation. A new strategy has recently been developed to overcome this difficulty involving the oxidative coupling of two nucleophiles [7], where the use of hydrocarbons as nucleophiles is considered by many to be an ideal ap- proach. There has been a recent increase in number of oxidative cross-coupling reactions being reported recently involving single electron transfer processes with first-row transition metal catalysts (i.e., $\mathrm{Cu}$ and $\mathrm{Fe}$ ), and radical oxidative coupling reactions of this type represent a promising development in green chemistry [8].

With respect to the development of new sustainable and green synthetic methods, the application of visible light as a renewable source of energy has attracted significant interest from organic chemist working in a variety of different fields [9-12]. Based on photo-induced single electron transfer processes, visible light photocatalysis provides a new strategy for the oxidation of $\mathrm{C}-\mathrm{H}$ bonds, and therefore represents an environmentally friendly approach to the construction of valuable chemicals under mild conditions. Although many organic molecules do not possess the structural features required to absorb

\footnotetext{
* Corresponding author. Tel: +86-27-68754672; E-mail: aiwenlei@whu.edu.cn

This work was supported by the National Basic Research Program of China (973 Program, 2012CB725302, 2011CB808600), the National Natural Science Foundation of China $(21390400,21272180,21302148)$, the Specialized Research Fund for the Doctoral Program of Higher Education of China (20120141130002), the Program for Changjiang Scholars and Innovative Research Team in University (IRT1030), the Ministry of Science and Technology of China (2012YQ120060), and the Program of Introducing Talents of Discipline to Universities of China (111 Program). DOI: 10.1016/S1872-2067(15)60885-3 | http://www.sciencedirect.com/science/journal/18722067 | Chin. J. Catal., Vol. 36, No. 9, September 2015
} 


$$
\begin{aligned}
& \text { Transition-metal catalyzed oxidative cross-coupling reactions } \\
& \mathrm{Nu}^{1}+\mathrm{Nu}^{2} \underset{[\mathrm{O}]}{\stackrel{[\mathrm{TM}]}{\longrightarrow}} \mathrm{Nu}^{1}-\mathrm{Nu}^{2} \\
& \text { Photoredox catalyzed oxidative cross-coupling reactions } \\
& \mathrm{Nu}^{1}+\mathrm{Nu}^{2} \underset{[\mathrm{O}]}{\stackrel{\text { PS }], \text { Light }}{\longrightarrow}} \mathrm{Nu}^{1}-\mathrm{Nu}^{2} \\
& \mathrm{Nu}=\text { Nucleophiles, } \mathrm{TM}=\text { Transition-metal, } \\
& \mathrm{O}=\text { Oxidants, } \mathrm{PS}=\text { Photosensitizer }
\end{aligned}
$$

Scheme 1. Visible light-photocatalyzed oxidative cross-coupling reactions.

visible light, the use of visible light photocatalysts (photosensitizers) in conjunction with electron/energy transfer processes could allow for a wide variety of efficient photochemical reactions to be conducted under visible light irradiation conditions.

Although significant developments have been achieved in transition-metal catalyzed oxidative cross-coupling reactions, synthetic strategies based on visible light photoredox reactions have emerged as efficient pathways for the formation of new chemical bonds between two nucleophiles during the last few years. Based on the mild and environmentally benign features of photoredox catalysis and the synthetic step economy of oxidative coupling reactions, the utilization of visible light photo-induced single electron transfer processes in oxidative cross-coupling reactions continues to attract increasing levels of attention (Scheme 1). Furthermore, the increased interest in this area has led to the development of many different types of photocatalyzed oxidative coupling reactions during the last 5 years, including the visible light-photocatalyzed oxidation/coupling reaction of amines, photo-induced oxidative decarboxylative coupling reactions and cross-coupling hydrogen evolution (CCHE) reactions. To date, several important reviews have been published providing a summary of fundamental organic transformations [13-19]. The aim of this review, however, is to highlight the recent development of visible light-photocatalyzed oxidative coupling reactions.

\section{Visible light-photocatalyzed oxidation of amines}

\subsection{Visible light-photocatalyzed oxidative cross-coupling} reactions with iminium ions as intermediate

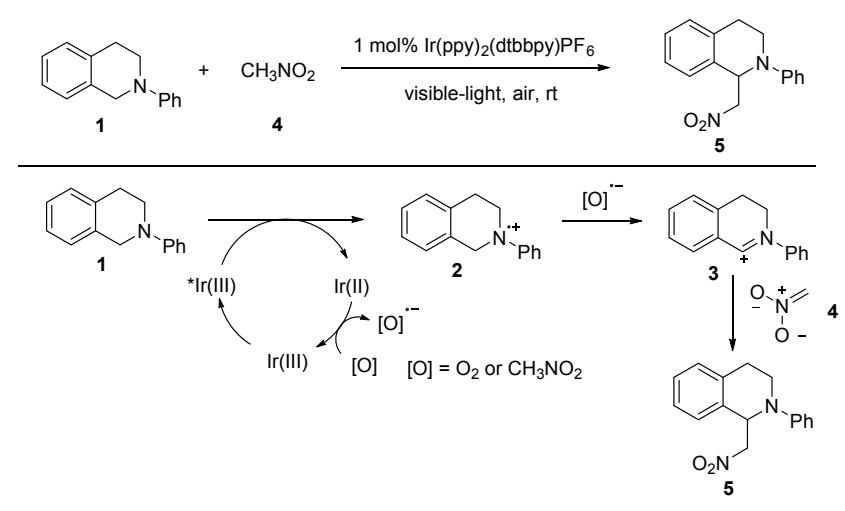

Scheme 2. Photoredox-catalyzed oxidative aza-Henry reaction.

The visible light-photocatalyzed oxidation of an $s p^{3} \mathrm{C}-\mathrm{H}$ bond adjacent to the $\mathrm{N}$ atom of a tertiary amine would provide access to an activated iminium ion, which could be trapped with a wide range of different nucleophiles to yield the direct coupling products. Photocatalyzed oxidative cross-coupling pathways of this type have been shown to be powerful protocols for the functionalization of amines. For example, Stephenson et al. [20] reported an oxidative aza-Henry reaction under photoredox conditions in 2010, which proceeded via the formation of an iminium ion intermediate (Scheme 2). Notably, this work provided the first example of the visible light mediated functionalization of an $\mathrm{s} p^{3} \mathrm{C}-\mathrm{H}$ bond adjacent to a nitrogen atom. The results of this study also revealed that visible light and the catalyst were both required for a successful conversion, and that the absence of oxygen resulted in much lower yields of the product. Furthermore, it was revealed that oxygen and $\mathrm{CH}_{3} \mathrm{NO}_{2}$ could both act as oxidants in this transformation. Based on a series of Stern-Volmer studies, the authors went on to propose a mechanism for this transformation. Briefly, visible light excitation of the $\mathrm{Ir}^{3+}$ catalyst followed by reductive quenching would lead to the formation of a radical cation of tetrahydroisoquinoline 2 . The authors proposed that oxygen could play a critical role in the reaction. The corresponding superoxide radical anion could abstract a $\mathrm{H}$ atom from the trialkylammonium radical cation to give the iminium ion. Nucle-

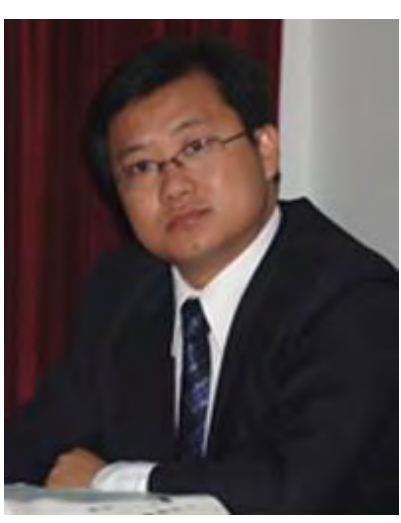

Aiwen Lei received his PhD degree (2000) (with Prof. Xiyan Lu) at Shanghai Institute of Organic Chemistry, Chinese Academy of Science (CAS). He then moved to Pennsylvania State University, U.S.A., and worked with Prof. Xumu Zhang as a postdoctoral fellow. In 2003, he joined Stanford University, working with Prof. James P. Collman as a research associate. He became a full professor at College of Chemistry and Molecular Sciences, Wuhan University, China in 2005. His research focuses on: (1) oxidative-coupling, a novel approaches and understanding toward bond formations and (2) physical organic chemistry in modern coupling reactions. He has published more than 170 papers in international journals with a total SCI citation of $>4000$, and the total impact factor over 1100. In 2007, he was hired as Luojia Distinguished Professor. In 2010, he won the National Science Fund for Distinguished Young Scholar. In 2012, he won the First Class Prize of Hubei Province Natural Science Award. In 2013, Prof. Lei attended the 15th Asian Chemical Congress and won the Asian Rising Star Award. Then in 2014, he won the 4th Chinese Chemical Society-Royal Society of Chemistry Young Chemist Award. In the same year, he has been selected as a Changjiang Scholar Chair Professor by the Chinese Ministry of Education. 


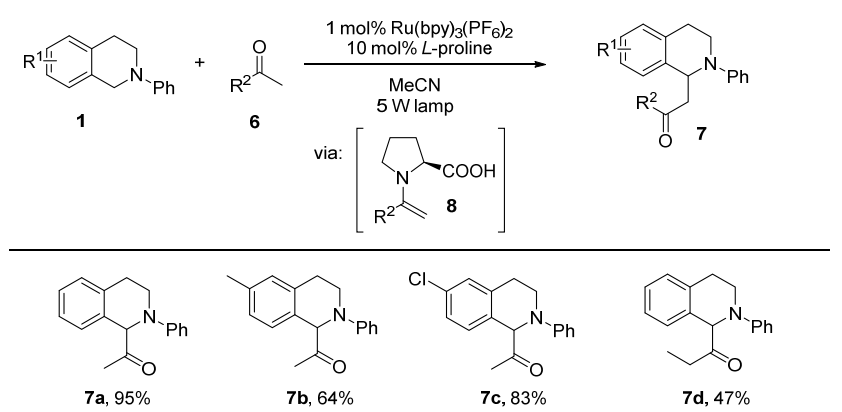

Scheme 3. Photoredox-catalyzed $s p^{3} \mathrm{C}-\mathrm{H}$ functionalization to form a new $\mathrm{C}-\mathrm{C}$ bond.

ophilic attack of 4 onto the iminium ion would provide the observed product $\mathbf{5}$.

A dual catalytic system was subsequently developed for this reaction by Rueping et al. [21] involving a combination of photoredox catalysis and organocatalysis (Scheme 3). Under these reaction conditions, it was possible to convert an enolizable ketone into a nucleophilic enamine intermediate $\mathbf{8}$ in the presence of $L$-proline, and this enamine intermediate could then react with the photocatalytically generated iminium ion $\mathbf{3}$ to give the Mannich-type addition product. A variety of different $\mathrm{N}$-aryl-tetrahydroisoquinolines have been subjected to this photooxidation/Mannich reaction to provide the corresponding products in good to excellent yields. However, long-chain ketones were found to be unsuitable as substrates for this transformation.

In a series of subsequent reports, Rueping's group went on to investigate a variety of other photocatalyzed oxidative coupling reactions, which culminated in the development of the oxidative $\alpha$-cyanation [22] and $\alpha$-phosphorylation [23] of tertiary amines 1 under visible light photoredox catalytic conditions (Scheme 4). Rueping's group also reported the development of a visible light-photocatalyzed alkynylation reaction for the preparation of tetrahydroisoquinoline derivatives by combining photoredox catalysis and copper catalysis [24].

Ensuing works by the groups of König [25], Wu [26] and Tan [27] towards the $\alpha-\mathrm{C}-\mathrm{H}$ oxidation of tertiary amines using photoredox catalysis further extended this methodology to a wide range of nucleophiles, including nitroalkanes, dialkyl phosponates, malononitrile and dialkyl malonates, which were successfully employed as coupling partners with tetrahydroi-

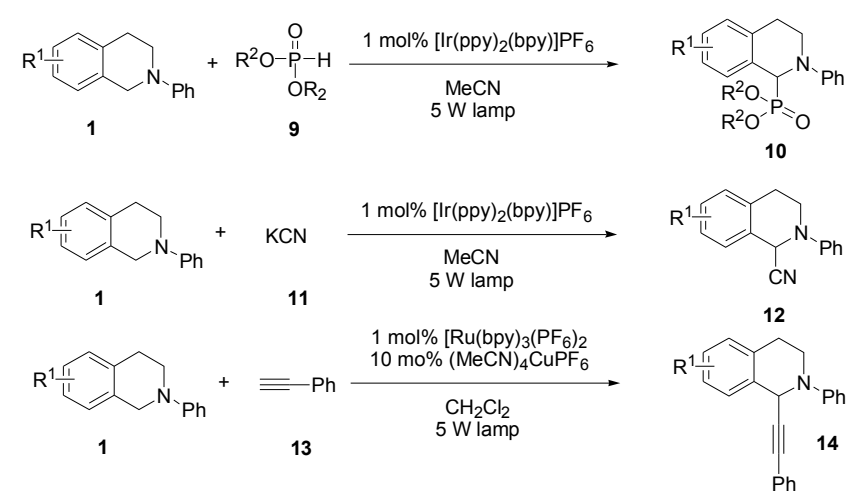

Scheme 4. Photoredox-catalyzed $\alpha$-cyanation, $\alpha$-phosphorylation and $\alpha$-alkynylation reactions of tetrahydroisoquinolines.

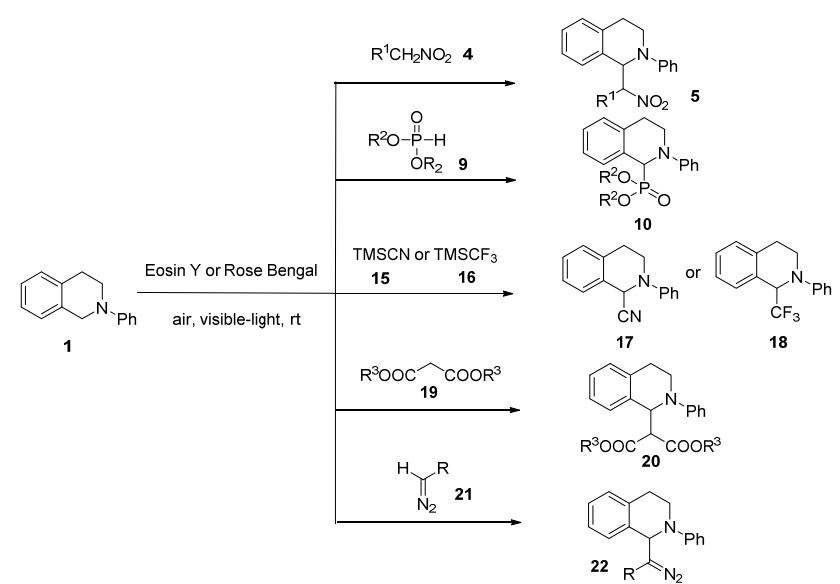

Scheme 5. Visible light photoredox-catalyzed oxidative cross-coupling reactions using organic dyes as photocatalysts.

soquinoline derivatives (Scheme 5). In these studies, eosin Y and Rose Bengal, which are famous organic dyes, were used as photocatalysts. Significantly, molecular oxygen has been shown to be responsible for accelerating these aerobic photocatalytic reactions. Furthermore, electron spin resonance (ESR) measurements collected by Wu's group provided direct evidence for the formation of a superoxide radical anion $\left(\mathrm{O}_{2}{ }^{--}\right)$rather than singlet oxygen during the visible light irradiation process. Notably, Tan's group reported that the $\alpha$-cyanation and $\alpha$-trifluoromethylation reactions of tertiary amines could be achieved using a combination of graphene oxide and Rose Bengal. In 2014, Zhou et al. [28] reported the development of a visible light-induced oxidative cross-coupling reaction between tertiary amines and diazo compounds. In a similar manner to previous reports, air or oxygen was used as an oxidant in this study to afford various $\beta$-amino- $\alpha$-diazo adducts in good yields.

In 2012, Stephenson et al. [29] reported the development of a new and more versatile approach for the functionalization of $\alpha$-amino $\mathrm{C}-\mathrm{H}$ bonds using visible light photoredox catalysis, and improved their initial system using $\mathrm{BrCCl}_{3}$ as an external oxidant to replace oxygen (Scheme 6). Notably, this method also exhibited a high level of compatibility towards a broad range of nucleophiles. Furthermore, the reaction system was removed from blue LED irradiation immediately after the complete conversion of the tertiary amines to the corresponding iminium intermediate $\mathbf{3}$ to avoid the formation of any undesired by-products.

In 2012, Rovis et al. [30] reported a productive dual-catalysis mode for the asymmetric $\alpha$-acylation of tertiary

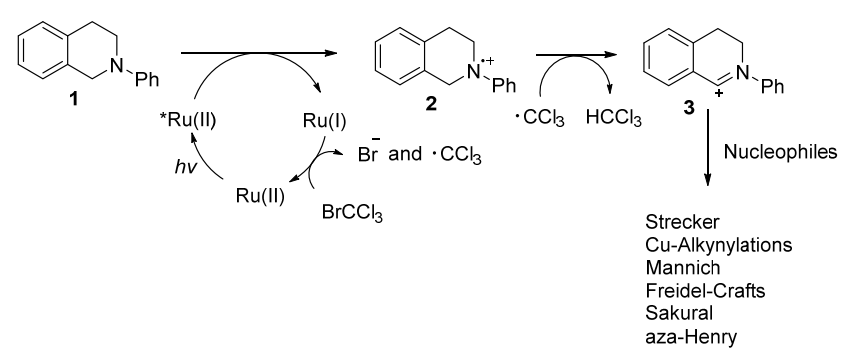

Scheme 6. Visible light photoredox-catalyzed oxidative cross-coupling using $\mathrm{BrCCl}_{3}$ as an external oxidant. 


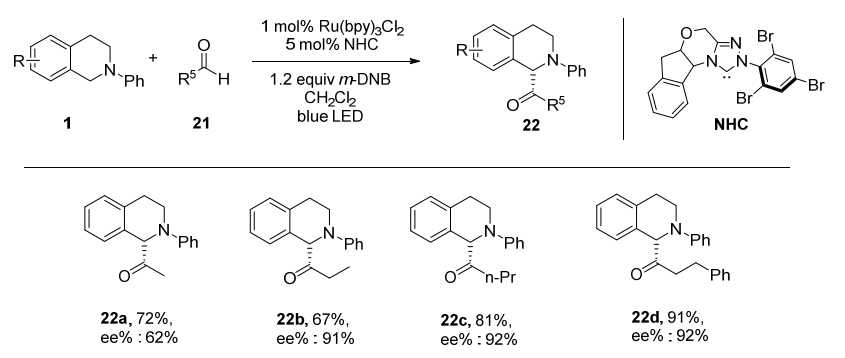

Scheme 7. Asymmetric $\alpha$-acylation of tertiary amines using a combination of photocatalysis and NHC catalysis.

amines (Scheme 7). Based on this powerful combination of $\mathrm{N}$-heterocyclic carbene (NHC) catalysis and visible light photoredox catalysis, Rovis's group successfully achieved the direct asymmetric functionalization of $\mathrm{sp}^{3} \mathrm{C}-\mathrm{H}$ bonds with a wide range of aldehydes. Using the methodology developed by Stephenson for the visible light-mediated formation of iminium ions with $m$-dinitrobenzene ( $m$-DNB) as an oxidant, Rovis's group investigated the reactions of these intermediates with nucleophiles generated in situ using an NHC catalyst to give the desired C-C coupling products. However, further work is still required to expand the substratescope of this reaction to more challenging aromatic aldehydes.

The photochemical properties of $\mathrm{Au}$ and $\mathrm{Pt}(\mathrm{II})$-complexes are fascinating. In 2012, Che's group [31] and Zhu's group [32] reported their efforts towards the use of organogold(III) complexesto catalyze the direct $\mathrm{s} p^{3} \mathrm{C}-\mathrm{H}$ functionalization of tertiary amines using visible light irradiation conditions under an oxygen atmosphere (Scheme 8). More recently, Wu et al. [33] reported the use of a $\mathrm{Pt}(\mathrm{II})$-complex as an efficient photocatalyst for the functionalization of $\mathrm{sp}^{3} \mathrm{C}-\mathrm{H}$ bonds following the addition of 2.0 equivalents of $\mathrm{FeSO}_{4}$. In the presence of $\mathrm{FeSO}_{4}$, the

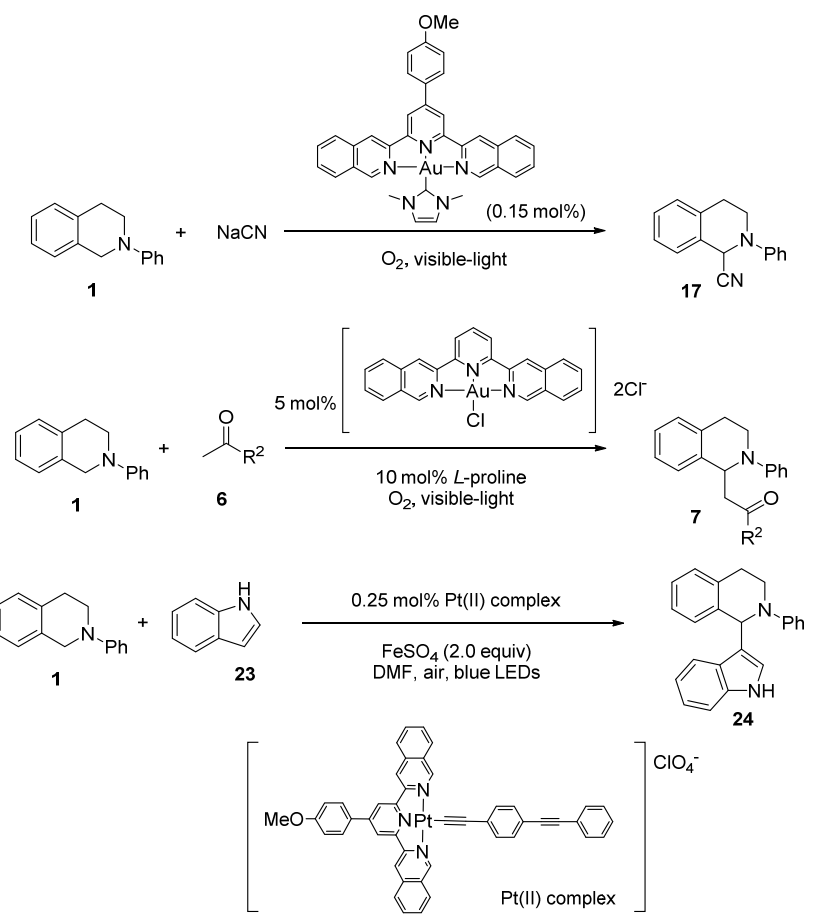

Scheme 8. Visible light photoredox-catalyzed oxidative cross-coupling reactions with $\mathrm{Au}$ and $\mathrm{Pt}$ complexes.

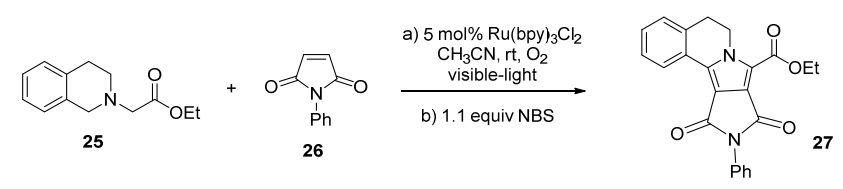

Scheme 9. Photocatalytic cascade strategy for the construction ofpyrrolo[2,1-a]isoquinolines.

corresponding amide could not be detected under visible light irradiation conditions, but the desired cross-coupling product was exclusively obtained under ambient air conditions.

Iminium ions generated via visible light photocatalysis have been reported to undergo [3+2] cycloaddition reactions with azomethine ylides (Scheme 9) [34]. In 2011, Xiao's group reported a tandem photocatalytic oxidation/[3+2] cycloaddition/oxidative aromatization sequence for the synthesis of pyrrolo[2,1-a]isoquinolines, which was initiated by visible light. It is noteworthy that this method provided access to a wide range of biologically active natural products. According to this process, the azomethine ylide generated from tetrahydroisoquinoline 25 were reacted with maleimides $\mathbf{2 6}$ under air or pure oxygen to give the [3+2] cycloaddition product 27. Rueping's group also reported a similar [3+2] cycloaddition reaction using visible light photoredox catalysis [35].

As demonstrated by the examples provided above, the substrates for these photocatalytic reactions are mainly limited to tetrahydroisoquinolines, and further work aimed at expanding the substrate scope of these visible light-mediated reactions is highly desirable. The reduction potential of amides is greater than that of the corresponding amines, making it much more difficult for amides to be directly oxidized. In 2012, Stephenson's group reported the development of a visible light-mediated Friedel-Crafts amidoalkylation reaction using persulfate, which proceeded via the oxidative quenching cycle of $\mathrm{Ru}(\mathrm{bpy}){ }_{3} \mathrm{Cl}_{2}$ (Scheme 10) [36]. The key step in this process was found to be oxidation of the dialkylamides. Furthermore, alcohols and electron-rich arenes performed as effective nucleophiles for this reaction, with the corresponding $\mathrm{C}-\mathrm{O}$ and $\mathrm{C}-\mathrm{C}$ bonds being formed with high yields and selectivities via a reactive $\mathrm{N}$-acyliminium intermediate. Persulfate $\left(\mathrm{S}_{2} \mathrm{O}_{8}{ }^{2-}\right)$ can be used as effective oxidative quencher for the excited-state of $\mathrm{Ru}(\mathrm{bpy})_{3^{2+}}$, and the resulting sulfate radical anion can be used

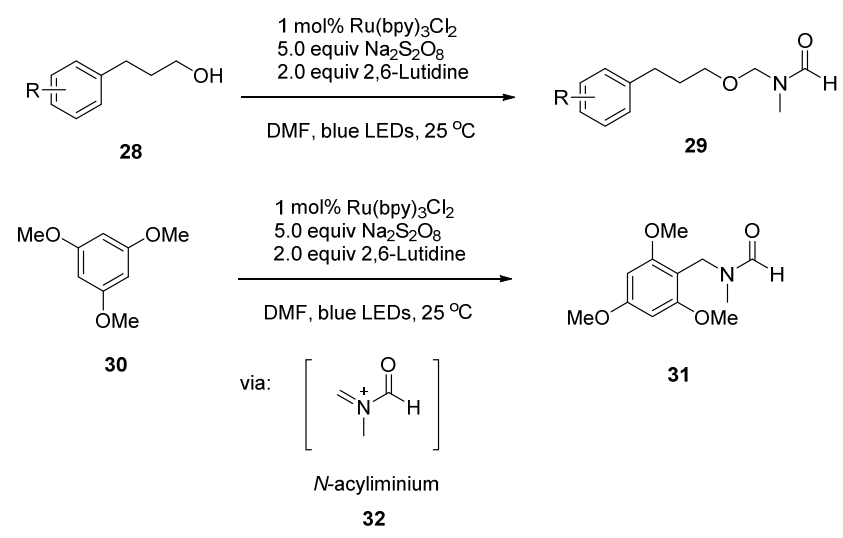

Scheme 10. Visible light-induced formation of $\mathrm{C}-\mathrm{O}$ and $\mathrm{C}-\mathrm{C}$ bonds using dialkylamides. 


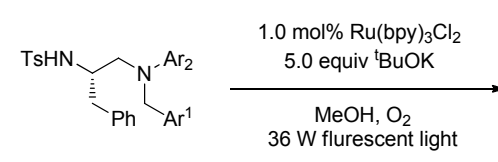

33

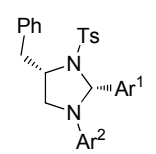

34

$91 \% \sim 94 \%$
dr $8: 1 \sim 19: 1$
Scheme 11. Visible light-induced intramolecular cyclization for the formation of highly substituted tetrahydroimidazoles.

to abstract a hydrogen atom from the amide to provide an $\alpha$-amino radical, which would allow for the generation of the $\mathrm{N}$-acyliminium ion $\mathbf{3 2}$ via a photocatalyzed oxidation.

In 2011, Xiao et al. [37] reported the development of a visible light-photocatalyzed intramolecular cyclization reaction. The reactive iminium ion intermediate involved in this reaction was generated from an amine substrate in the presence of a photoredox catalyst and $\mathrm{O}_{2}$ under visible light irradiation conditions (Scheme 11). The iminium ion then underwent an intramolecular cyclization reaction to afford a highly substituted tetrahydroimidazole derivative with high diastereoselectivity in good yield. The stereochemical outcome of this reaction was rationalized on the basis that the $R e$-face of the iminium ion would be attacked much more readily than the Si-face because of steric repulsion from the pendant aryl groups.

\subsection{Visible light-photocatalyzed oxidative coupling reactions with $\alpha$-aminoalkyl radical as the intermediate}

Although the generation of iminium ions by the two electron oxidation of amines and the subsequent reaction of the iminium ions with various nucleophiles has been studied extensively, reports pertaining to the use of $\alpha$-aminoalkyl radicals formed by single electron oxidation processes as reactive intermediates in photocatalyzed oxidative cross-coupling reactions are scarce. In 2012, Nishibayashi et al. [38] reported the development of a reaction for the direct $s p^{3} \mathrm{C}-\mathrm{H}$ amination of benzocyclic amines via an $\alpha$-aminoalkyl radical using photoredox catalysis (Scheme 12). Di-tert-butyl azodicarboxylate was selected as the $\mathrm{N}$ source in this particular case and the visible light-mediated addition of the $\alpha$-aminoalkyl radical 39 to azodicarboxylate ester $\mathbf{3 6}$ gave the corresponding $\mathrm{C}-\mathrm{N}$ bond formation product 37. According to the proposed mechanism for this reaction, the amine would be oxidized by the excited photocatalyst to give the radical cation $\mathbf{3 8}$, which would be

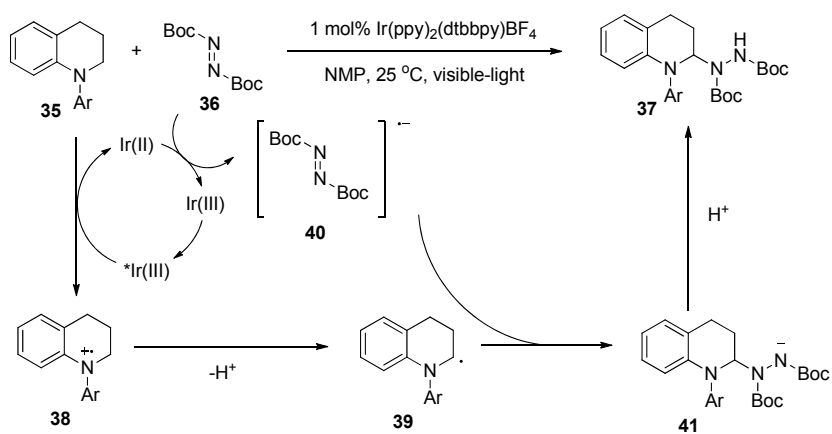

Scheme 12. Visible light-mediated oxidative radical addition via an $\alpha$-aminoalkyl radical.

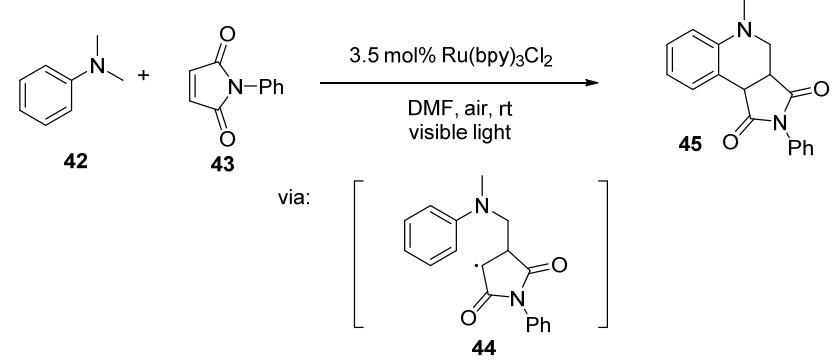

Scheme 13. Reaction of tertiary anilines with maleimides under visible light photoredox catalysis.

deprotonated to give the $\alpha$-aminoalkyl radical 44. Subsequent reduction of azodicarboxylate ester 36 by Ir(II), would afford the corresponding radical anion 40, which would undergo a radical-radical coupling reaction with $\mathbf{4 0}$ to give $\mathbf{4 1}$. Subsequent protonation of $\mathbf{4 1}$ would then give the product $\mathbf{3 7}$. It is also possible to direct the radical addition of $\mathbf{3 9}$ to 36 to give intermediate $\mathbf{4 1}$.

In early 2013, Bian et al. [39] reported that $\mathrm{N}, \mathrm{N}$-dimethylaniline derivatives could react with $\mathrm{N}$-aryl- and $\mathrm{N}$-benzylmaleimides to give the corresponding tetrahydroquinoline products using visible light photoredox catalysis with air as the terminal oxidant (Scheme 13). The formation of the tetrahydroquinoline products observed in this study proceeded via the addition of $\alpha$-aminoalkyl radicals to the $\mathrm{C}=\mathrm{C}$ double bond of maleimide 43 . The resulting radical intermediate 44 then underwent a free radical cyclization to give the desired product 45. Around the same time, Rueping et al. [40] also reported a similar tandem protocol for the application of $\alpha$-aminoalkyl radicals in organic synthesis (Scheme 14). Two different products could be obtained from the same starting material in this reaction depending on whether the transformation was conducted in the presence or absence of oxygen. In a similar manner to the work reported by Bian's group, Rueping suggested that compound $\mathbf{4 7}$ was formed via a radical addition/cyclization pathway in the presence of $\mathrm{O}_{2}$. However, in the absence of $\mathrm{O}_{2}$, the $\alpha$-aminoalkyl radical underwent an intermolecular addition process to the electron-deficient alkene bond to afford 48.

In 2014, Zhou et al. [41] used a photoredox strategy to generate $\alpha$-aminoalkyl radicals for the synthesis of 3 -acylindoles via the intramolecular oxidative cyclization of $O$-alkynylated $\mathrm{N}, \mathrm{N}$-dialkylamines (Scheme 15). According to the proposed mechanism for this reaction, a single-electron transfer (SET)

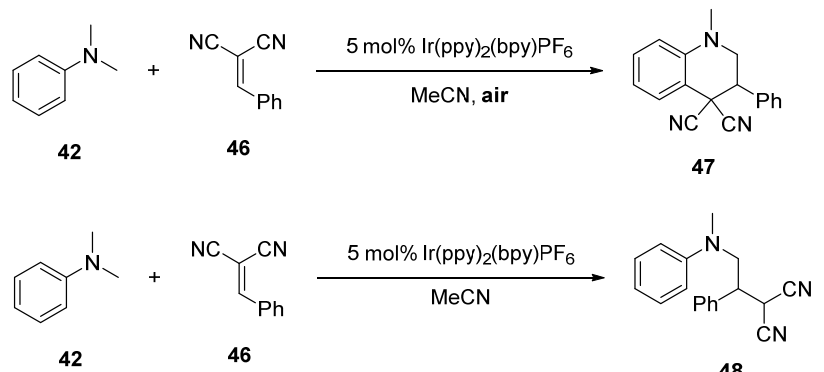

Scheme 14. Oxygen switch in visible light photoredox catalysis: radical additions and cyclizations. 


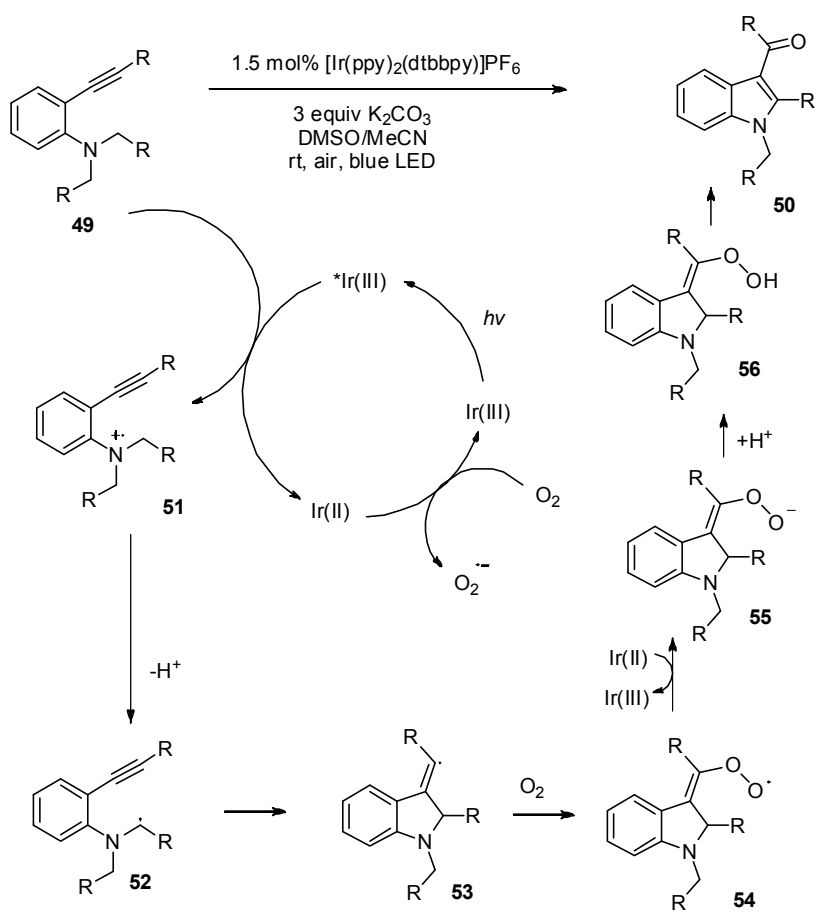

Scheme 15. Synthesis of 3-acylindoles via a visible light-induced intramolecular oxidative cyclization reaction.

between substrate 49 and $\operatorname{Ir}(\mathrm{III}) *$ would lead to the formation of Ir(II) and the corresponding radical cation 51, which would undergo a deprotonation step to give the $\alpha$-amino alkyl radical 52. The subsequent intramolecular radical addition reaction of the carbon radical in $\mathbf{5 2}$ to the triple bond of the alkyne would give the vinyl radical $\mathbf{5 3}$, which would be trapped by oxygen to generate the superoxide radical 54. The reduction of $\mathbf{5 4}$ with Ir(II) would then regenerate the Ir(III) catalyst together with the formation of intermediate $\mathbf{5 5}$. Another possible route to $\mathbf{5 5}$ would involve the addition of the superoxide radical anion $\mathrm{O}_{2} \cdot-$ to vinyl radical 53. Finally, the protonation of $\mathbf{5 5}$ would give the vinyl hydrogen peroxide 56, which would undergo an intramolecular hydrogen abstraction step to afford the 3-acylindole 50.

\subsection{Visible light-photocatalyzed $\mathrm{C}-\mathrm{H}$ functionalization of secondary amines}

In 2012, Rueping et al. [42] developed a relay catalytic system for the functionalization of glycine derivatives and dipeptides (Scheme 16). Importantly, this methodology extended the scope of photoredox-catalyzed $\mathrm{C}-\mathrm{H}$ functionalization reactions beyond the use of tertiary amines. The authors found that the addition of $\mathrm{Zn}(\mathrm{OAc})_{2}$ led to significant improvements in the efficiency of the $\mathrm{C}-\mathrm{H}$ arylation reaction. In a similar manner to the studies described above, this reaction begins with a SET process from the secondary amine substrate to the excited-state of the photocatalyst to give the radical cation $\mathbf{6 0}$, which would be converted to intermediate 61. Alternatively, the glycine derivatives could be directly oxidized to $\mathbf{6 1}$ by the superoxide anion generated during the course of the reaction. The activated electrophile $\mathbf{6 2}$ could be formed in the presence

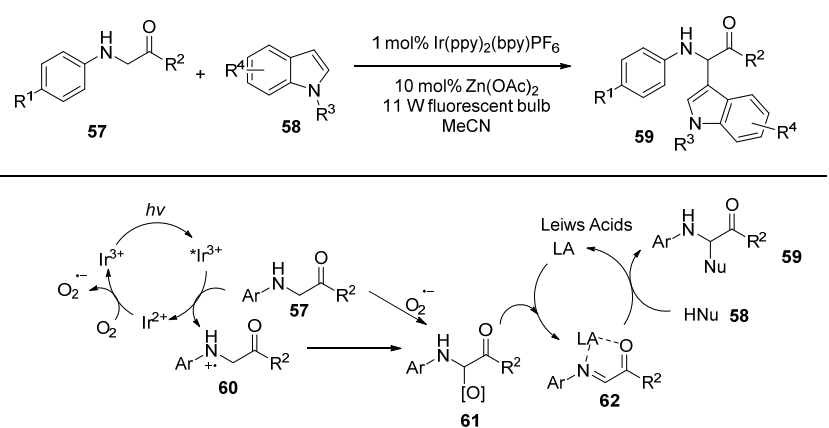

Scheme 16. Visible light-induced $s p^{3} \mathrm{C}-\mathrm{H}$ functionalization of secondary amines.

of the Lewis acid catalyst, and could subsequently react with nucleophile $\mathbf{5 8}$ to give the desired product $\mathbf{5 9}$.

As mentioned above, $N$-centered radical cations can be generated by the direct oxidation of amines using a photoredox catalyst. Under visible light photoredox conditions, the fate of nitrogen-centered radical cations has been shown to follow one of two reaction pathways, including (1) the conversion of the radical into an iminium ion with concomitant release of a hydrogen radical or (2) the conversion of the radical into an $\alpha$-amino radical by deprotonation. Further to these two pathways, it also possible that the radical could undergo a direct electrophilic addition to an alkene, as reported by Zheng's group in 2012 (Scheme 17) [43]. Zheng's group developed a new approach to $\mathrm{N}$-arylindoles via a tandem oxidative $\mathrm{C}-\mathrm{N}$ bond formation/aromatization sequence. The $\mathrm{Ru}(\mathrm{bpz}) 3^{2+}$ photocatalyst used in this sequence was found to be capable of oxidizing $N$ - $p$-methoxyphenylanilines such as 63 to the corresponding radical cations. It is noteworthy that the addition of silica gel to the reaction mixture led to a significant increase in the rate of the reaction. This increase in the rate was attributed to the silica gel adsorbing oxygen and behaving as a source of protons, as well as facilitating the oxidation of the substrate through a proton-coupled electron transfer process. The mild aerobic oxidation conditions of this reaction were compatible with variety broad range of functional groups, although a $p$-alkoxyphenyl group on the $\mathrm{N}$ atom was found to be critical for the reaction.

In 2012, Li et al. [44] reported the development of an aerobic visible light-mediated reaction for the formation of 2-substituted benzothiazoles via the radical cyclization of thioanilides (Scheme 18). Oxygen served as a terminal oxidant in this oxidative cyclization reaction. However, this reaction was

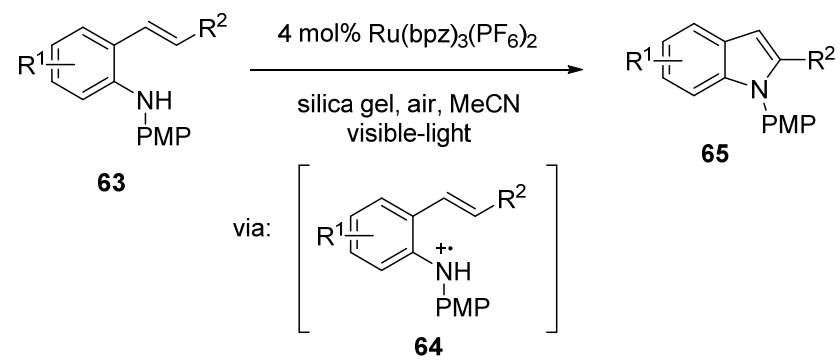

Scheme 17. Visible light-induced $s p^{2} \mathrm{C}-\mathrm{H}$ functionalization of secondary amines. 


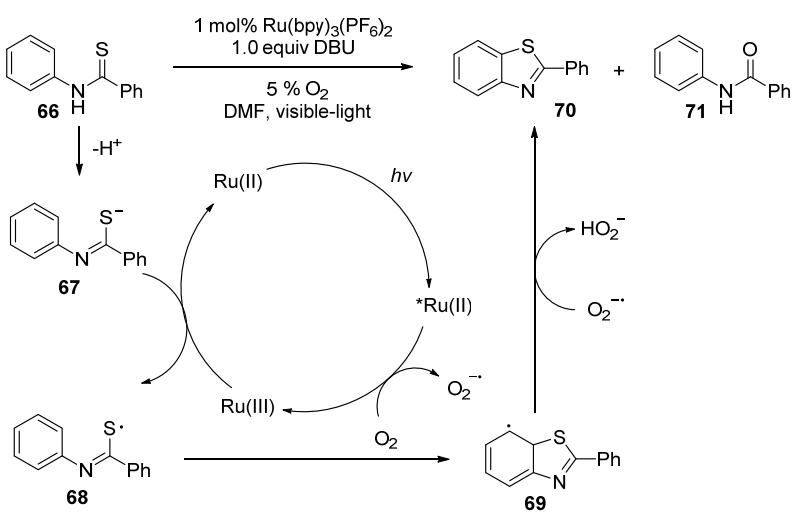

Scheme 18. Visible light-induced oxidative cyclization and $\mathrm{s} p^{2} \mathrm{C}-\mathrm{H}$ functionalization of secondary amines.

found to be particularly sensitive to the concentration of oxygen in the reaction system. This reaction worked well under low oxygen conditions, although the intramolecular cyclization was almost completely suppressed in the absence of oxygen, with 71 being formed as the major product. The proposed mechanism for this reaction starts with the oxidative quenching of the excited-state of $\mathrm{Ru}(\mathrm{II})$ species by $\mathrm{O}_{2}$. The subsequent deprotonation of $\mathbf{6 6}$ would give the corresponding imidothiolate anion 67, which is much susceptible to oxidation than 66 . The single-electron oxidation of $\mathbf{6 7}$ by $\mathrm{Ru}(\mathrm{III})$ would then give the $S$-centered radical 68 , which would undergo a radical addition reaction to the benzene ring to give dienyl radical 69 . Superoxide would then abstract a $\mathrm{H}$ atom from radical 69 to give the desired benzothiazole product $\mathbf{7 0}$ and hydrogen peroxide.

\section{Visible light-photocatalyzed oxidative decarboxylative coupling reaction}

The oxidative decarboxylation of carboxylic acids is a fundamental and important process in nature. The availability, high stability and low cost of carboxylic acids make them extremely promising raw materials for chemical synthesis. Compared with transition-metal-catalyzed decarboxylation processes, photocatalyzed oxidative decarboxylation reactions represent a novel and efficient approach for the construction of chemical bonds under mild conditions.

In 2013, Zhu et al. [45] reported a visible light-photocatalyzed decarboxylation/radical $\mathrm{C}-\mathrm{H}$ functionalization reaction that proceeded efficiently at room temperature (Scheme 19). This strategy therefore provided a facile approach for the construction of 3,3-disubstituted oxindoles, which represent a privileged class of heterocyclic scaffolds that can be found in a wide range of natural products and biologically active drugs. Given that carboxylic acids can readily undergo ligand metathesis with phenyliodine diacetate, a wide variety of primary, secondary and tertiary aliphatic carboxylic acids have been reacted in this way to afford the corresponding oxindoles in good yields. Furthermore, a broad range of different functional groups were found to be compatible with these conditions.

In 2013, using $\mathrm{O}_{2}$ as the sole oxidant, Lei et al. [46] reported

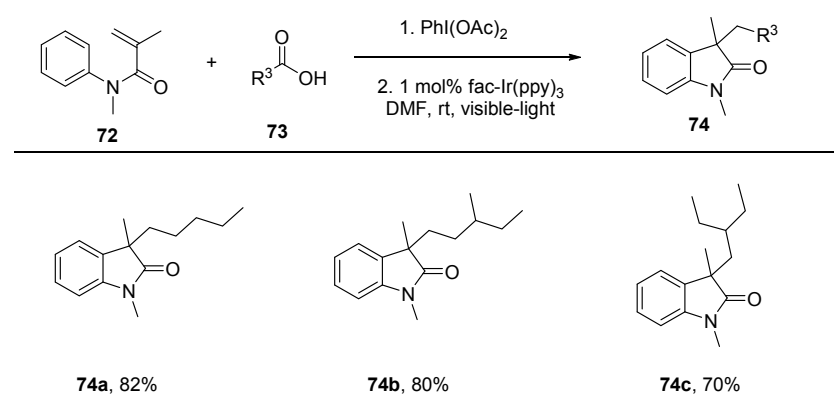

Scheme 19. Visible light-photocatalyzed decarboxylation/C-H functionalization cascade reaction.

the radical oxidative decarboxylative coupling of $\alpha$-keto acids with amines by photocatalysis to give the corresponding amides (Scheme 20). In this case, the $\alpha$-keto acids were used as precursors for acyl radicals, which were subsequently reacted with a variety of different amines to give the corresponding amide radical anions. The radical anions were then subjected to a further radical oxidation to give the desired amide products. Based on the results of an EPR experiment, the authors proposed a reductive quenching mechanism for this reaction. According to the mechanism, the irradiation of $\mathrm{Ru}(\mathrm{Phen})_{3} \mathrm{Cl}_{2}$ with visible light would lead to the formation of the excited state of the photocatalyst, which would be reduced by an amine to form $\mathrm{Ru}(\mathrm{I})$. A single-electron-transfer (SET) from $\mathrm{Ru}(\mathrm{I})$ to oxygen would provide the superoxide radical anion and regenerate the $\mathrm{Ru}(\mathrm{II})$. This method could also be applied to the construction of heterocyclic compounds such as benzimidazoles, benzoxazoles and benzothiazolesusing aniline substrates bearingan $\mathrm{NH}_{2}, \mathrm{OH}$ or SH group at their ortho-position, respectively. The results of a DFT calculation also supported that the formation of the radical anion was a facile process in this reaction.

Chen et al. [47] recently reported the development of a creative catalytic system based on the combination of hypervalent iodine reagents with a photocatalyst (Scheme 21) [47]. This new system allowed for a series of alkyl-substituted alkenes to be synthesized via a deboronation/decarboxylation sequence under mild conditions. During the course of this study, Chen's group isolated a novel benziodoxole-vinyl carboxylic acid intermediate form the reaction mixture, which they could be playing a critical role in the catalytic cycle. A mechanism for

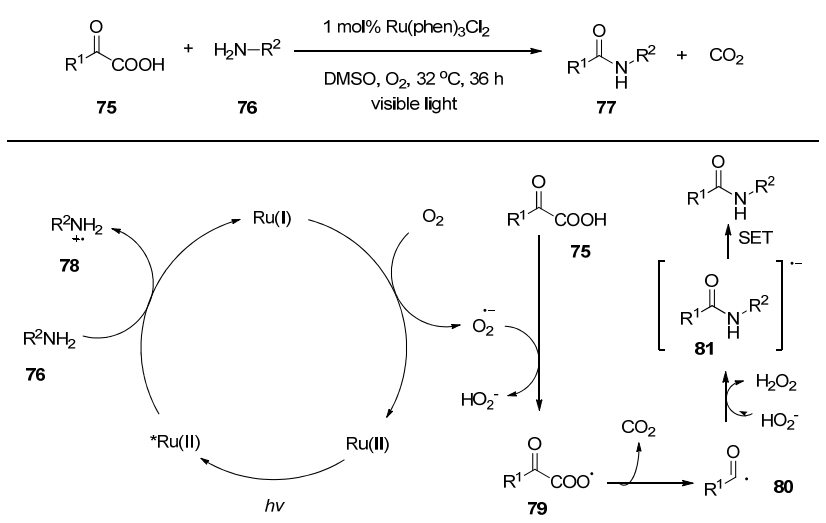

Scheme 20. Visible light-mediated decarboxylation/oxidative amidation of $\alpha$-keto acids with amines 

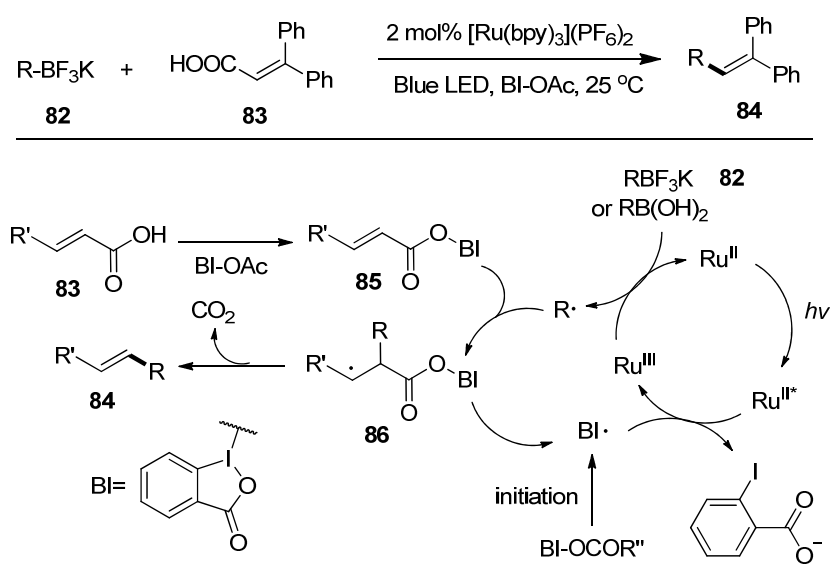

Scheme 21. Chemoselective deboronative/decarboxylative alkenylation by photoredox catalysis.

this reaction was proposed based on a series of experimental investigations. According to this mechanism, the vinyl carboxylic acid substrate would react with BI-OAc to form a benziodoxole vinyl carboxylic acid complex in situ, which would subsequently decompose to generate a carbon-based radical. This radical would then oxidize the photoexcited $\left[\mathrm{Ru}(\mathrm{bpy})_{3}\right]^{2+*}$ to $\left[\mathrm{Ru}(\mathrm{bpy})_{3}\right]^{3+}$, which would be reduced by the alkyl trifluoroborate or boronic acid to complete the catalytic cycle. At the same time, an alkyl R radical would be generated, which would add to the iodine intermediate to form a new radical species. Adduct 86 would then undergo a benziodoxole-facilitated decarboxylation to release a benziodoxole radical together with the alkene product $\mathbf{8 4}$.

\section{Other type reactions}

Along with the development of photocatalyzed oxidative coupling reactions, there have been an increasing number of reports pertaining to new bond formation modes. In 1993, a new chiral photocatalyst, $\Delta$-Ru(menbpy) $3^{2+}$, was synthesized and utilized in the oxidative dimerization of naphthol (Scheme 22) [48]. Using $\mathrm{Co}_{\text {(acac) }} 3$ as the stoichiometric oxidant, this reaction proceeded smoothly to give 1,1'-bi-2-napthol $(\mathbf{8 8})$ in good yields. An oxidative quenching mechanism was proposed, and the formation of the $\alpha$-carbonyl radical was considered to

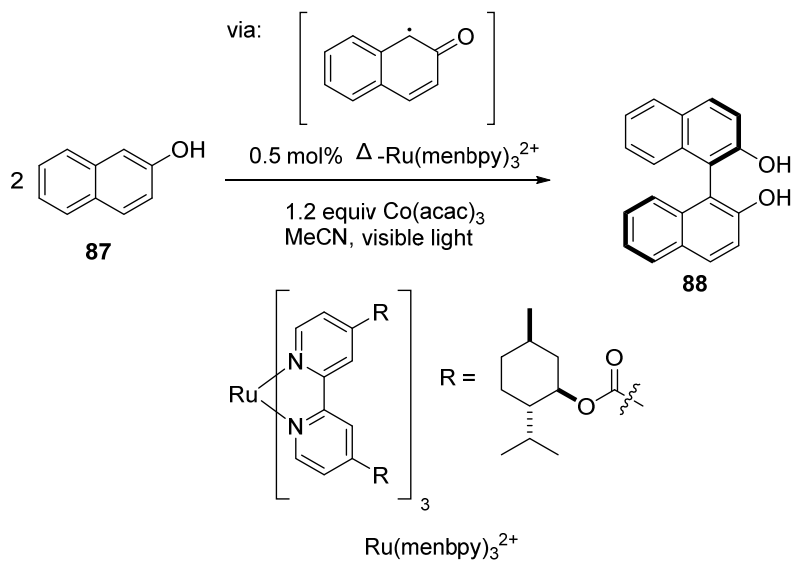

Scheme 22. Oxidative biaryl coupling with a chiral photocatalyst.
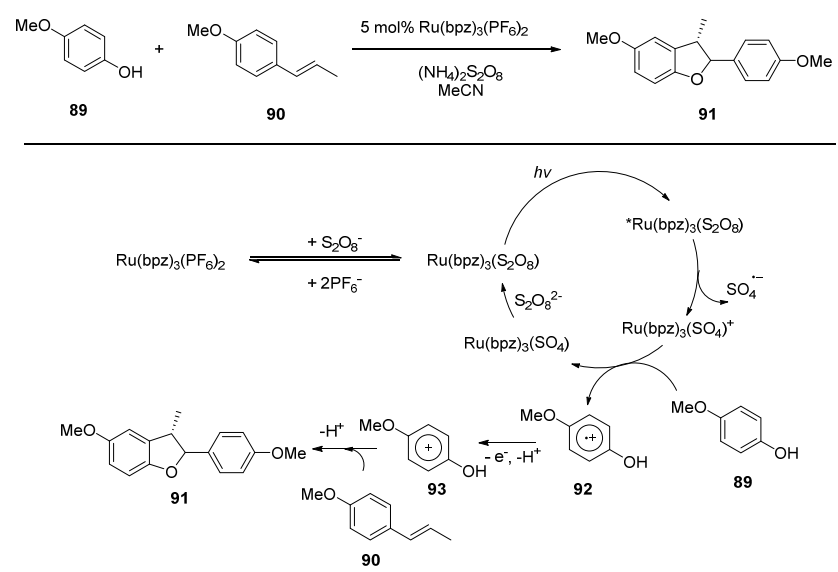

Scheme 23. Photocatalytic synthesis of dihydrobenzofurans via the oxidative [3+2] cycloaddition of phenols.

be the key step.

The activation of the $\mathrm{s} p^{2} \mathrm{C}-\mathrm{H}$ bonds of phenols was recentlyexplored by Yoon's groups [49], which resulted in the development of a new protocol for the oxidative [3+2] cycloaddition of phenols and alkenes that provided access to a series of dihydrobenzofuran products (Scheme 23). In this report, ammonium persulfate was used as an easy-to-handle, benign terminal oxidant. This oxidative coupling reaction required electron-rich phenols bearing alkoxy substituents at the 2- or 4-position, although a broad range of coupling partners were well tolerated under the reaction conditions. It was reported that an orange precipitate formed in the reaction mixture that could be used to catalyze the [3+2] cycloaddition, and so the authors proposed that the precipitate was $\mathrm{Ru}(\mathrm{bpz})_{3}\left(\mathrm{~S}_{2} \mathrm{O}_{8}\right)$. According to the proposed mechanism for this reaction, the excited state of this salt would undergo an oxidative quenching step to give the active oxidant $\mathrm{Ru}(\mathrm{bpz})_{3^{3+}}$. The oxidation of the phenol substrate would generate the corresponding phenoxonium cation $\mathbf{9 2}$, which would be trapped by olefin $\mathbf{9 0}$ to give the dihydrobenzofuran product $\mathbf{9 1 .}$

In 2014, MacMillan et al. [50] developed a photoredox-mediated reaction for the direct $\alpha$-arylation of cyclic and acyclic ethers with electron-deficient heteroarenes, which proceeded according to a Minisci-type mechanism (Scheme 24). This method showed a broad scope with regard to both the dialkyl ether and heteroarene substrates to give the $\alpha$-oxyalkylated arene products in high yields. Oxidation of the excited state of Ir(III) by a persulfate anion afforded the Ir(IV) complex together with the sulfate radical anion. It was reported that the $\alpha$-oxyalkyl radical was generated via a hydrogen-atom-transfer (HAT) pathway between the dialkyl ether and the sulfate radical anion. The radical addition reaction would then occur according to a Minisci-type pathway to provide the amine radical cation, which would lose a proton and an electron to give the $\alpha$-aryl ether products.

Direct oxidative $\mathrm{C}-\mathrm{H}$ functionalization reactions involving arenes are important transformations in metal-catalyzed synthetic organic chemistry, and generally require the addition of a stoichiometric amount of a suitable metal salt. In 2014, Rueping et al. [51] reported the development of a combined 

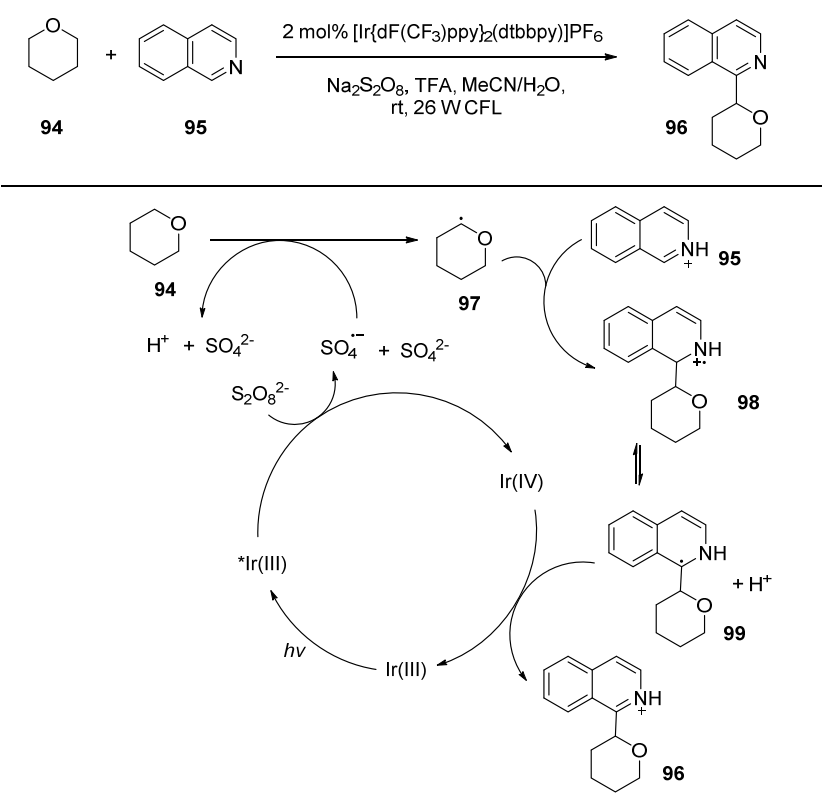

Scheme 24. Photoredox-mediated $\mathrm{C}-\mathrm{H}$ functionalization and the Minisci reaction.

$\mathrm{Rh} /$ photoredox catalytic system for the $\mathrm{C}-\mathrm{H}$ functionalization of arenes to provide the oxidative Heck products using $\mathrm{O}_{2}$ as the terminal oxidant (Scheme 25). The use of $\mathrm{Ru}(\mathrm{bpy})_{3}\left(\mathrm{PF}_{6}\right)_{2}$ in the Rh-catalyzed $s p^{2} \mathrm{C}-\mathrm{H}$ activation of benzamides with olefins afforded excellent yields of the olefinated products. Subsequent mechanistic studies revealed that air rather than chlorobenzene worked well as the terminal oxidant.

Subsequent reports from the same group revealed that the combination of $\mathrm{Pd}$ and photoredox catalysis in the presence of visible light allowed for the $\mathrm{C}-\mathrm{H}$ olefination of aromatic enamines and the synthesis of the indoles (Scheme 26). [52] Using catalytic amounts of the photocatalyst, it was possible to avoid the typically high loadings of the external oxidant and metal salt. Control experiments showed that no other oxidant was present during this reaction. Furthermore, the superoxide anions formed in situ in the presence of oxygen and the photoredox catalyst functioned as the external oxidant. When this reaction was performed with $100 \mathrm{~mol} \%$ of the photoredox catalyst under an Ar atmosphere, the corresponding product was isolated in $46 \%$ yield. This result therefore demonstrated that the Pd catalyst could be reoxidized by the photoredox catalyst.

In 2014, Rueping's group reported the development of a photoredox reactionfor the olefination of phenol ethers using a

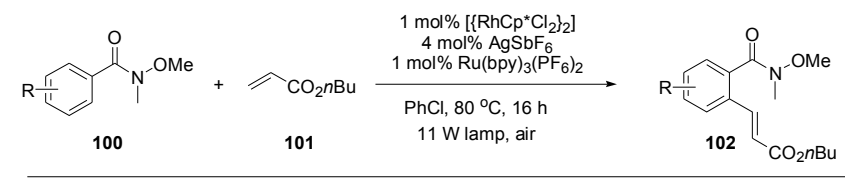

102a, $91 \%$ (102b, $72 \%$

Scheme 25. Photoredox-catalyzed oxidative Heck reaction.
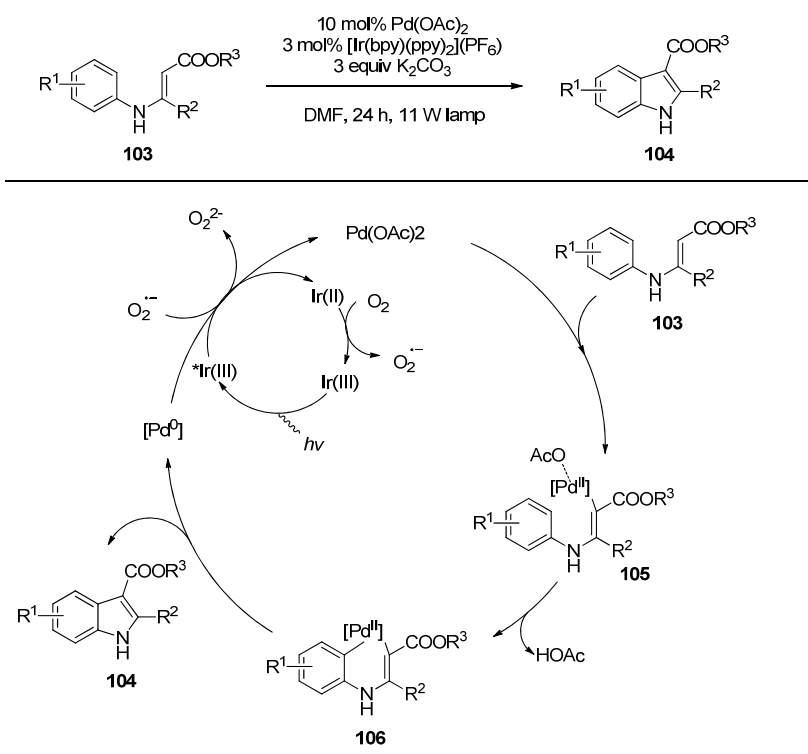

Scheme 26. Photoredox-catalyzed oxidative $\mathrm{C}-\mathrm{H}$ olefination of aromatic enamines.

$\mathrm{Ru}$ catalyst (Scheme 27) [53]. Rueping's group also evaluated the effects of the different components on the success of the reaction, including the ruthenium dimer, the silver salt, the photoredox catalyst and molecular oxygen. The highlight of this method was found to be the unique interaction between the metal and the photoredox catalyst, which allowed for the direct re-oxidation of the metal hydride intermediate to complete the catalytic cycle. It is noteworthy that this system can be used for oxidant-sensitive molecules.

\section{Cross-coupling hydrogen evolution (CCHE) reactions}

Oxidative coupling reactions are some of the most desirable and powerful tools for the direct formation of new chemical bonds from two carbon nucleophiles. For example, oxidative coupling reactions can be used to achieve the direct formation of a new $\mathrm{C}-\mathrm{C}$ bond from two different $\mathrm{C}-\mathrm{H}$ bonds using a suitable oxidant. However, these reactions generally require the addition of a sacrificial oxidant, which can lead to the development of numerous waste products and oxidative side reactions. Cross-coupling hydrogen evolution (CCHE) reactions using photoredox catalysis have recently emerged as a powerful approach for the formation of $\mathrm{C}-\mathrm{C}$ bonds, while circumventing the need for stoichiometric oxidants or the pre-functionalization of substrates.

In 2013, Wu et al. [54] reported the development of an external oxidant-free cross-coupling reaction for the formation of C-C bonds with $\mathrm{H}_{2}$ evolution under visible light irradiation conditions (Scheme 28). In this particular study, the organic dye eosin $\mathrm{Y}$ was used as a photosensitizer to convert the ter-

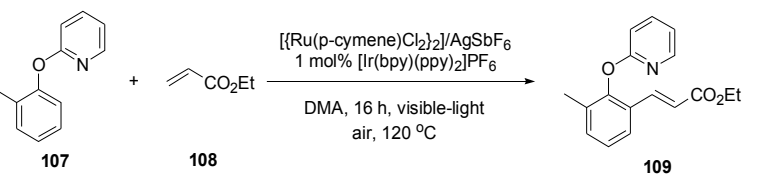

Scheme 27. C-H functionalization of phenols using combined ruthenium and photoredox catalysis. 


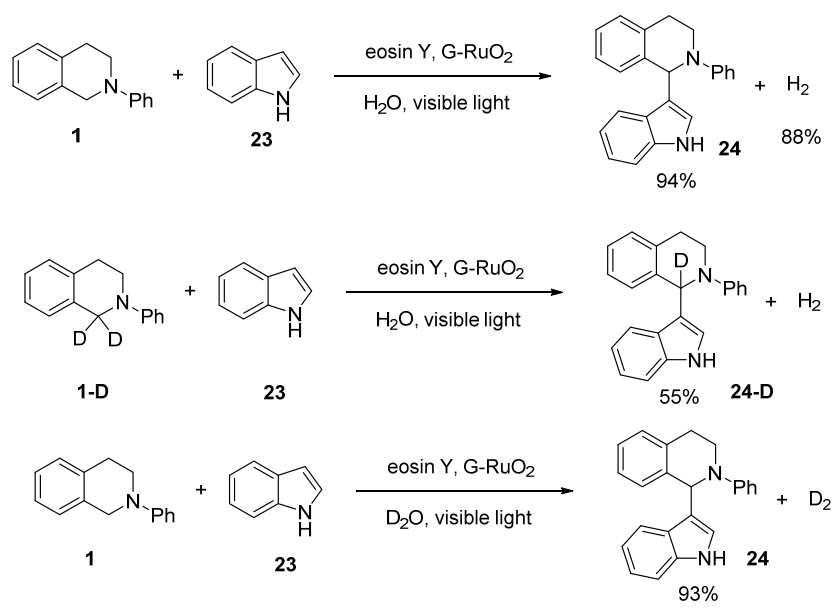

Scheme 28. C-C bond formation via an oxidant-free cross-coupling reaction under visible light irradiation conditions.

tiary amine substrates to the corresponding iminium ions, which were trapped by nucleophiles to form the new C-C bonds. It is noteworthy that a graphene-supported $\mathrm{RuO}_{2}$ nanocomposite (G-RuO2) was used as a catalyst to reduce the proton eliminated from the $\mathrm{C}-\mathrm{H}$ bonds of the substrates. A deuterium-labeling experiment was conducted, which revealed that the proton exchange process between the protons released from the substrate and water was quick. Therefore, when $\mathrm{D}_{2} \mathrm{O}$ was used as the solvent, $\mathrm{D}_{2}$ was generated instead of $\mathrm{H}_{2}$ as the only byproduct.

Wu's group went on to extend this strategy to the homo-coupling reactions of thiols to give the corresponding disulfides (Scheme 29) [55]. The irradiation of CdSe quantum dots (QDs) with visible light was found to result in the quantitative coupling of thiols to give disulfides products and $\mathrm{H}_{2}$ without the addition of any external sacrificial oxidants. Furthermore, the addition of nickel(II) salts to the system led to a significant improvement in the efficiency and rate of conversion. Subsequent mechanistic studies indicated that the CdSe QDs possessed many active surface sites that could be used to induce the photochemical transformation.

$\mathrm{Wu}$ et al. [56] also developed a homogenous catalyst, $\mathrm{Co}(\mathrm{dmgH})_{2} \mathrm{Cl}_{2}$ (dmgH=dimethylglyoximate), which they used to catalyze the cross-coupling reaction between isoquinolines and indoles (Scheme 30). In a similar manner to other studies in this area, the organic dye eosin $\mathrm{Y}$ was used as a photosensitizer to convert the tertiary amine substrates to the corresponding

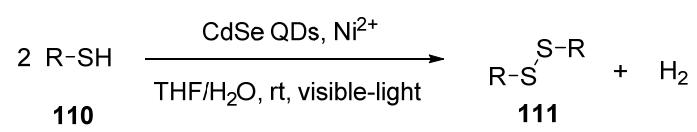

Scheme 29. S-S bond formation via an oxidant-free homo-coupling under visible light irradiation conditions using CdSe QDs.

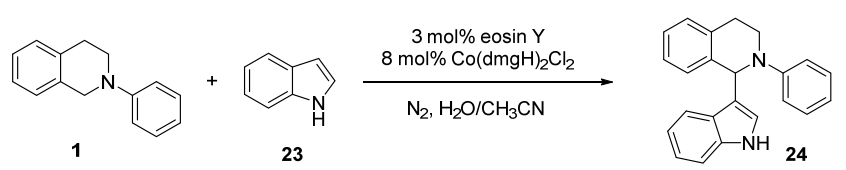

Scheme 30. Cross-coupling hydrogen evolution reaction in a homogeneous solution. iminium ions, and the proton released during this process was reduced by a cobalt catalyst to give an almost identical amount of $\mathrm{H}_{2}$. In contrast to other heterogeneous systems reported in the literature, this system could be used in a mixture of organic solvent and water, making it possible to expand the scope of this reaction to water-insoluble substrates.

\section{Conclusions and outlook}

Photoredox catalysis has been proven to be a valuable tool for the construction of new chemical bonds in synthetic chemistry. Along with the development of photoredox catalysis, a large number of novel visible light photoredox-catalyzed oxidative cross-coupling reactions featuring mild and efficient conditions have been reported in recent years. The mechanisms of these photocatalyzed oxidative coupling reactions often involve a single electron transfer (SET) process between the photocatalyst and the substrate. The reductive quenching or oxidative quenching of the excited photocatalyst generally leads to the formation of a diverse range of reactive intermediates, followed by the further coupling/oxidation of these intermediates to allow for the formation of new chemical bonds. As we have shown, these active intermediates include iminium ions, $\alpha$-aminoalkyl radicals, $S$-centered radicals, $\alpha$-carbonyl radical and $\alpha$-oxyalkyl radicals, among others. Furthermore, the combination of a photoredox catalyst with a metal catalyst, organocatalyst or proton-reductive-catalyst has recently been used to achieve direct photocatalyzed $\mathrm{C}-\mathrm{H}$ activation and oxidant-free $\mathrm{C}-\mathrm{H} / \mathrm{X}-\mathrm{H}$ functionalization reactions, thereby highlighting the potential of photocatalyzed oxidative coupling reactions.

There are still a large number of challenges in the field of photoredox-catalyzed oxidative coupling reactions. For example, the general scope of photoredox-catalyzed oxidative coupling reaction involving readily oxidized $\mathrm{C}-\mathrm{H}$ bonds remains limited. Furthermore, the extension of this methodology to non-amine-based substrates remains a significant challenge, given that amines have been utilized almost exclusively as electron donors in photocatalytic reactions.

\section{References}

[1] de Meijere A, Diederich F. Metal-Catalyzed Cross-Coupling Reactions, 2nd Ed. Wiley-VCH: Weinheim, Germany, 2004

[2] Engle K M, Mei T S, Wasa M, Yu J Q. Acc Chem Res, 2012, 45 : 788

[3] Colby D A, Tsai A S, Bergman R G, Ellman J A. Acc Chem Res, 2011, 45: 814

[4] Arockiam P B, Bruneau C, Dixneuf P H. Chem Rev, 2012, 112: 5879

[5] Skouta R, Li C J. Tetrahedron, 2008, 64: 4917

[6] Boorman T C, Larrosa I. Chem Soc Rev, 2011, 40: 1910

[7] Liu C, Zhang H, Shi W, Lei A. Chem Rev, 2011, 111: 1780

[8] Liu C, Liu D, Lei A. Acc Chem Res, 2014, 47: 3459

[9] Ishitani O, Pac C, Sakurai H. J Org Chem, 1983, 48: 2941

[10] Mandler D, Willner I. J Am Chem Soc, 1984, 106: 5352

[11] Pac C, Ihama M, Yasuda M, Miyauchi Y, Sakurai H. J Am Chem Soc, 1981, 103: 6495 


\title{
Graphical Abstract
}

Chin. J. Catal., 2015, 36: 1428-1439 doi: 10.1016/S1872-2067(15)60885-3

\section{Advances in visible-light-mediated oxidative coupling reactions}

Guoting Zhang, Changliang Bian, Aiwen Lei* Wuhan University

Recent advances in visible light photoredox-catalyzed cross-coupling reactions, including the visible light-photocatalyzed oxidation/coupling reaction of amines, oxidative decarboxylative coupling reactions and cross-coupling hydrogen evolution reactions have been reviewed together with several other reactions.
Photoredox catalyzed oxidative cross-coupling reactions

$$
\mathrm{Nu}^{1}+\mathrm{Nu}^{2} \stackrel{[\mathrm{PS}] \text {, Light }}{[\mathrm{O}]} \mathrm{Nu}^{1}-\mathrm{Nu}^{2}
$$

$\mathrm{Nu}=$ Nucleophiles, $\mathrm{TM}=$ Transition-metal, $\mathrm{O}=$ Oxidants, $\mathrm{PS}=$ Photosensitizer
[12] Pac C, Miyauchi Y, Ishitani O, Ihama M, Yasuda M, Sakurai H. J Org Chem, 1984, 49: 26

[13] Narayanam J M, Stephenson C R. Chem Soc Rev, 2011, 40: 102

[14] Nicewicz D A, Nguyen T M. ACS Catal, 2014, 4: 355

[15] Prier C K, Rankic D A, MacMillan D W. Chem Rev, 2013, 113: 5322

[16] Xie J, Jin H, Xu P, Zhu C. Tetrahedron Lett, 2014, 55: 36

[17] Xuan J, Xiao W J. Angew Chem Int Ed, 2012, 51: 6828

[18] Yoon T P, Ischay M A, Du J. Nat Chem, 2010, 2: 527

[19] Xi Y, Yi H, Lei A. Org Biomol Chem, 2013, 11: 2387

[20] Condie A G, Gonzalez-Gomez J C, Stephenson C R J. J Am Chem Soc, 2010, 132: 1464

[21] Rueping M, Vila C, Koenigs R M, Poscharny K, Fabry D C. Chem Commun, 2011, 47: 2360

[22] Rueping M, Zhu S Q, Koenigs R M. Chem Commun, 2011, 47 12709

[23] Rueping M, Zhu S Q, Koenigs R M. Chem Commun, 2011, 47: 8679

[24] Rueping M, Koenigs R M, Poscharny K, Fabry D C, Leonori D, Vila C. Chem Eur J, 2012, 18: 5170

[25] Hari D P, König B. Org Lett, 2011, 13: 3852

[26] Liu Q, Li Y N, Zhang H H, Chen B, Tung C H, Wu L Z. Chem Eur J, 2012, 18: 620

[27] Pan Y, Wang S, Kee C W, Dubuisson E, Yang Y, Loh K P, Tan C H. Green Chem, 2011, 13: 3341

[28] Xiao T, Li L, Lin G, Mao Z W, Zhou L. Org Lett, 2014, 16: 4232

[29] Freeman D B, Furst L, Condie A G, Stephenson C R J. Org Lett, 2012, 14: 94

[30] DiRocco D A, Rovis T. J Am Chem Soc, 2012, 134: 8094

[31] To W P, Tong G S M, Lu W, Ma C, Liu J, Chow A L F, Che C M. Angew Chem Int Ed, 2012, 51: 2654

[32] Xue Q, Xie J, Jin H, Cheng Y, Zhu C. Org Biomol Chem, 2013, 11: 1606

[33] Zhong J J, Meng Q Y, Wang G X, Liu Q, Chen B, Feng K, Tung C H, Wu L Z. Chem Eur J, 2013, 19: 6443

[34] Zou Y Q, Lu L Q, Fu L, Chang N J, Rong J, Chen J R, Xiao W J. Angew Chem Int Ed, 2011, 50: 7171

[35] Rueping M, Leonori D, Poisson T. Chem Commun, 2011, 47:
9615

[36] Dai C, Meschini F, Narayanam J M R, Stephenson C R J. J Org Chem, 2012, 77: 4425

[37] Xuan J, Cheng Y, An J, Lu L Q, Zhang X X, Xiao W J. Chem Commun, 2011, 47: 8337

[38] Miyake Y, Nakajima K, Nishibayashi Y. Chem Eur J, 2012, 18 16473

[39] Ju X, Li D, Li W, Yu W, Bian F. Adv Synth Catal, 2012, 354: 3561

[40] Zhu S, Das A, Bui L, Zhou H, Curran D P, Rueping M. J Am Chem Soc, 2013, 135: 1823

[41] Zhang P, Xiao T, Xiong S, Dong X, Zhou L. Org Lett, 2014, 16: 3264

[42] Zhu S, Rueping M. Chem Commun, 2012, 48: 11960

[43] Maity S, Zheng N. Angew Chem Int Ed, 2012, 51: 9562

[44] Cheng Y, Yang J, Qu Y, Li P. Org Lett, 2011, 14: 98

[45] Xie J, Xu P, Li H, Xue Q, Jin H, Cheng Y, Zhu C. Chem Commun, 2013, 49: 5672

[46] Liu J, Liu Q, Yi H, Qin C, Bai R, Qi X, Lan Y, Lei A. Angew Chem Int Ed, 2014, 53: 502

[47] Huang H, Jia K, Chen Y. Angew Chem Int Ed, 2015, 54: 1881

[48] Hamada T, Ishida H, Usui S, Watanabe Y, Tsumura K, Ohkubo K. J Chem Soc Chem Commun, 1993, (11): 909

[49] Blum T R, Zhu Y, Nordeen S A, Yoon T P. Angew Chem Int Ed, 2014, 53: 11056

[50] Jin J, MacMillan D W C. Angew Chem Int Ed, 2015, 54: 1565

[51] Fabry D C, Zoller J, Raja S, Rueping M. Angew Chem Int Ed, 2014, 53: 10228

[52] Zoller J, Fabry D C, Ronge M A, Rueping M. Angew Chem Int Ed, 2014, 53: 13264

[53] Fabry D C, Ronge M A, Zoller J, Rueping M. Angew Chem Int Ed, 2015, 54: 2801

[54] Meng Q Y, Zhong J J, Liu Q Gao X W, Zhang H H, Lei L, Li Z J, Feng K, Chen B, Tung C H, Wu L Z. J Am Chem Soc, 2013, 135: 19052

[55] Li X B, Li Z J, Gao Y J, Meng Q Y, Yu S, Weiss R G, Tung C H, Wu L Z. Angew Chem Int Ed, 2014, 53: 2085

[56] Zhong J J, Mencvg Q Y, Liu B, Li X B, Gao X W, Lei T, Wu C J, Li Z J, Tung C H, Wu L Z. Org Lett, 2014, 16: 1988

\section{可见光参与的氧化偶联反应研究进展}

\author{
张国亭 ${ }^{\mathrm{a}}$, 边长亮 ${ }^{\mathrm{a}}$, 雷爱文, ${ }^{\mathrm{a},{ }^{*}}$ \\ $a$ 武汉大学化学与分子科学学院, 高等研究所, 湖北武汉 430072 \\ b 江西师范大学国家单糖化学合成工程技术研究中心, 江西南昌 330022
}


摘要: 实现资源和能源利用高效化、操作简单化、条件温和化、环境友好化以及产物高效选择性是有机合成的重要研究方向, 而 探索绿色温和条件下构建化学键的有效方法是有机合成领域的基本挑战之一. 伴随着金属有机化学的发展, 过渡金属催化的偶 联反应已经成为构建碳一碳和碳一杂键的有效手段, 而传统的交叉偶联一般是基于亲核试剂与亲电试剂之间的反应, 需要进行预 官能团化和再官能团化的步骤. 近年来, 在此基础上发展起来的氧化偶联反应利用合适的氧化剂实现两个亲核试剂直接构建化 学键也得到了国内外有机化学家的广泛关注. 氧化偶联反应的发展极大地提高了构建碳一碳键及碳一杂键的效率, 尤其是利用交 叉脱氢偶联实现直接的碳-氢键或杂-氢键的活化直接构建化学键, 避免了传统偶联过程中的预官能团化步骤, 为直接利用简单 的原料实现高效、复杂的有机合成开辟了一条新的道路. 越来越多的第一过渡金属催化的氧化偶联反应涉及到单电子转移的过 程, 这种自由基氧化偶联模式在绿色化学的发展中具有光明的前景.

可见光是一种可再生的资源, 可见光催化符合绿色合成、环境友好和可持续发展的理念, 在有机合成领域中引起了广泛的关 注. 建立在光诱导的单电子转移过程的基础上, 可见光催化为实现温和条件下构建化学键提供了一种新的思路. 虽然很多的有机 分子不能有效吸收可见光, 但是利用可见光催化剂 (光敏剂) 在电子和能量转移过程中的独特优势, 能够有效实现在可见光作用 下的一系列光化学反应. 光催化是有机合成构建新物质的一种有效的手段, 随着光催化在有机合成领域中的发展, 一系列新型温 和而有效的可见光催化的氧化偶联反应也逐渐被报道. 虽然过渡金属催化的氧化偶联反应已经取得了重大的进展, 但是利用可 见光催化的策略以实现两个亲核试剂之间化学键的构建作为一个新的领域, 近年来才刚刚发展起来. 尤其是结合可见光催化条 件温和、环境友好的特点和氧化偶联反应的原子经济性特点, 将可见光诱导的单电子转移过程运用到交叉脱氢偶联反应, 引起了 广泛的关注. 光催化氧化偶联反应不仅解决了传统偶联中的步骤经济性和原子经济性的问题, 同时也具备了可见光反应温和环 保的特点.

近几年来已经发展了多种类型的光催化氧化偶联反应, 包括光催化氧化含氮化合物的偶联反应、光催化氧化脱羧偶联反应、 以及光催化交叉偶联放氢反应等. 但是在光催化氧化偶联领域的相关报道大多局限于含氮化合物和易氧化的底物的活化氧化, 因此任然存在着很多的挑战. 本文总结了最近几年来的不同反应类型的可见光催化的氧化偶联的研究和进展. 而对这些反应的 理解和认识, 可以为人们发展更多的高效率和高选择性的可见光催化氧化偶联反应提供帮助.

关键词: 氧化交叉偶联; 光催化; 可见光; 均相催化; 单电子转移

收稿日期: 2015-04-07. 接受日期: 2015-04-23. 出版日期: 2015-09-20.

*通讯联系人. 电话: (027)68754672; 电子信箱: aiwenlei@whu.edu.cn

基金来源: 国家重点基础研究发展计划(973计划, 2012CB725302, 2011CB808600); 国家自然科学基金(21390400, 21272180, 21302148); 高等学校博士学科点专项科研基金(20120141130002); 长江学者与创新团队发展计划 (IRT1030); 科技部 (2012YQ120060); 高等学校学科创新引智计划资助(111计划).

本文的英文电子版由Elsevier出版社在ScienceDirect上出版(http://www.sciencedirect.com/science/journal/18722067). 